\title{
EVALUATION OF LOCAL ADMINISTRATION OF SIMVASTATIN ON HEIGHT AND WIDTH OF THE HEALING EXTRACTION SOCKET IN RAT MANDIBLE
}

\author{
Youmna M. Sherif ${ }^{I} B D S$, Nawal El Masry ${ }^{2} P h D$, Sahar S. Karam ${ }^{3} P h D$, \\ Maha A. Nasra ${ }^{4} P h D$
}

\begin{abstract} new bone of the healing extraction socket and decreases bone resorption.

KEYWORDS: Simvastatin, Socket Healing, Bone Regeneration, Resorption.

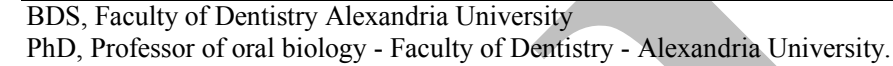

INTRODUCTION: studies concerning healing of extraction sockets revealed that sockets were filled with new bone by as much as two thirds in 40 days and completely filled with new bone in 10 weeks. There have been many studies demonstrating the bone-promoting effect of simvastatin local application in animal models. Simvastatin was shown to increase bone volume, bone formation rate, and bone compressive strength. The use of statins for bone regeneration is a promising and growing area of research.

OBJECTIVES: The aim of this study was to compare between the amounts of resorption that occurs in the healing extraction socket left to heal spontaneously to the amount of resorption that occurs in the healing extraction socket filled with simvastatin gel.

MATERIALS AND METHODS: Right and left first molars were extracted from 20 rats' mandibles'. Right side extraction sockets (Experimental) were filled with $2.5 \%$ simvastatin gel, while the left side sockets (Controls) were allowed to heal spontaneously. The rats were humanely sacrificed at $1^{\text {st }}, 2^{\text {nd }}, 3^{\text {rd }}$ and $4^{\text {th }}$ week postoperatively, and the specimens' height and width were measured using a bone caliper.

RESULTS: The mid-buccal height as well as the buccolingual width of the alveolar bone on the simvastatin-treated side was relatively higher and thicker than the control side indicating that less resorption had occurred on that side.

CONCLUSIONS: The present study provided evidence that a single topical application of $2.5 \%$ simvastatin gel improve the quality of the

\section{INTRODUCTION}

Statin drugs have become a mainstay in the treatment of high cholesterol level since the discovery in the 1970s that molecules produced by Penicillium citrinum, called citrinin and compactin (mevastatin), are potent inhibitors of an important enzyme in the cholesterol production pathway, 3hydroxy-3-methylglutaryl-CoA reductase (HMG-CoA reductase) (1).

Though the earliest HMG-CoA reductase inhibitors have never been marketed due to adverse effects seen in animals, it was not long until another naturally derived statin, lovastatin, was derived from Aspergillus terreus and has been found to have an acceptable toxicity profile. Since the discovery of the naturally occurring lovastatin, six additional statins have been introduced to the market. Two of these are semi-synthetic (simvastatin and pravastatin) and four are synthetic (fluvastatin, atorvastatin, rosuvastatin, and pitavastatin) (2).

The first experimental evidence in an animal model of the osteo-modulador effect of statins was reported by Mundy et al (3)who demonstrated that treatment with lovastatin, simvastatin, fluvastatin and mevastatin resulted in a significant increase (up to 2-3 times compared with controls) in the rates and bone formation markers, and that the effect of statins was comparable to that induced by treatment with bone morphogenetic protein-2 (BMP-2) and fibroblast growth factor, which are known stimulants of bone metabolism. Other studies conducted in animal models, replicated the effects of statins as stimulating bone formation (4).

The potential positive effect of statins on bone formation can be explained from three mechanisms: (a) the promotion of osteogenesis (b) suppression of apoptosis of osteoblasts and (c) inhibition of Osteoclastogenesis. The promotion of osteogenesis appears to be linked to mechanisms of prenylation as a posttranslational modification and necessary for certain key proteins in some signaling cascades (5).

Development and formation of the skeleton (ossification) occur by two distinct processes: intramembraneous and endochondral ossification. Both intramembraneous and endochondral bone ossification occur in close proximity to vascular ingrowth. Intramembraneous ossification is characterized by invasion of capillaries into the mesenchymal zone, and the emergence and differentiation of mesenchymal cells into mature osteoblasts. These osteoblasts constitutively deposit bone matrix leading to the formation of bone spicules. These spicules grow and develop eventually fusing with other spicules to form trabeculae. As the trabeculae increase in size and number they become interconnected forming woven bone (a disorganized weak structure with a high proportion of osteocytes), which eventually is replaced by more organized, stronger, lamellar bone. This type of ossification occurs during embryonic development and is involved in the development parts of the mandible (6).

The healing of an extraction socket is a specialized example of healing by second intention immediately after the removal of the tooth from the socket, blood fills the extraction site. Both intrinsic and extrinsic pathways of the clotting cascade are activated. The resultant fibrin meshwork containing entrapped red blood cells seals off the torn blood vessels and reduces the size of the extraction wound (7). 
The healing of normal extraction wounds in rats begins with the appearance of the epithelium on the second postoperative day and the end of the epithelization occurs on the eighth day. Formation of bone begins on the fourth day after the exodontia. The intense bone formation lasts until the twentieth postoperative day when the young bone fills the socket. Lamellar bone is present on $60^{\text {th }}$ days after extraction $(8,9)$.

In most situations, an extraction induces bone resorption, that is always more significant on the buccal side. This resorption leads to a reduction in vertical height of the ridge and a lingual displacement of its axis $(4,5)$.

However, regardless of the surgical technique used, a loss of volume in the transverse and vertical direction is evident in the systematic review of Hammerle et al (10) which calculated the horizontal loss to be $3.8 \mathrm{~mm}$ and the alveolar height to be $1.24 \mathrm{~mm}$ six months after extraction. Thus, the use of drugs that might regulate the factors that stimulate alveolar regeneration is an interesting possibility in oral surgery (11).

Tooth extraction procedures would take advantage of a local application because it allows a focused effect into specific bone sockets. Recent studies tested the effect of the local application of simvastatin associated with different carriers, such as gelatin (12) polylatic/polyglicolic acid and calcium sulfate (13), and have demonstrated potential to increase bone formation. However, there is not a consensus of an ideal carrier for the drug on bone defects and further studies are necessary (14).

To test the hypothesis that the topical administration of a single dose of simvastatin may improve alveolar bone regeneration this study was done by the extraction of the mandibular first molar, by which a space to retain simvastatin-containing gel is created while preventing bacterial infection and epithelial down growth. Aiming to compare between the amounts of resorption that occurs in the experimental groups to that occurring in the control groups, the specimens' heights and widths were measured at the extraction site using a bone caliper in both control and experimental groups. Statistical analyses were made then to indicate whether the different heights and widths showed significant or non-significant different rates of resorption.

\section{MATERIALS AND METHODS}

\section{Sample selection}

Twenty healthy adult Wistar rats weighing 150 to $200 \mathrm{~g}$ were randomly selected to be used in this study. Animals were obtained from the Institute of Medical Research, Alexandria University and were examined by the animal house veterinarian to exclude any disease.

\section{Grouping}

The selected animals were divided into four groups each consisting of five rats.

The animals were kept under proper nutritional and environmental condition in the animal house of Physiology Department Faculty of Medicine, Alexandria University

They were housed in specially designed wire mesh bottom cages, five animals per cage. The animals were supplied a regular diet during the whole experimental period. Animal groups were as follows;

Group I: (5 rats) were sacrificed after 1 week.

Group II :( 5 rats) were sacrificed after 2 weeks.

Group III :( 5 rats) were sacrificed after 3 weeks.

Group IV :( 5 rats) were sacrificed after 4 weeks.

\section{Materials}

Simvastatin was a kind gift from Medizen pharmaceutical industries, chitosan high molecular weight was a kind gift from Amriya pharmaceutical industries and all solvents were of analytical grad.

\section{Preparation of simvastatin gel}

Chitosan is a natural biodegradable, biocompatible and bioadhesive polymer was prepared by adding $4 \mathrm{~g}$ chitosan to $100 \mathrm{ml}(1 \% \mathrm{v} / \mathrm{v})$ acetic acid solution to form a gel under mild stirring conditions $(15,16)$. The obtained gel was refrigerated overnight to give a clear gel (16). Simvastatin was incorporated into the formulation by dispersion of $2.5 \mathrm{~g}$ of simvastatin in $97.5 \mathrm{~g}$ chitosan gel using a mortar and pestle.

\section{Methods}

In all animals, the extraction of the first molar was made on both right and left sides of the mandible. The right mandibular socket was filled with a dose of $0.1 \mathrm{ml}$ gel containing $2.5 \%$ simvastatin, whereas the left site was used as the control and therefore, it was left to heal spontaneously.

\section{Pre-operative preparation}

All animals were anesthetized by intraperitoneal administration of a 4:1 solution of ketamine/xylazine at a dose of $0.15 \mathrm{ml}$ per $100 \mathrm{~g}$ of body weight.

\section{Surgical procedure}

Teeth extractions were performed by the same operator with the same technique in all animals.

Initially, the rats were placed in a dorsal position. After that, the surrounding gingival tissues was carefully detached from the lower first molars with a dental explorer and teeth luxation were made using a Hollenback Carver followed by the tooth removal with some forceps, adapted around the cervical line of the tooth.

The right mandibular socket was filled with a gel containing $2.5 \%$ simvastatin, whereas the left site was used as control and, therefore, it was left to heal spontaneously. In both groups, soft tissues were closed with 8-0 interrupted sutures. The animals were randomly divided into 4 groups; each one composed of 5 rats, and then humanely sacrificed at 1 st $, 2^{\text {nd }}, 3^{\text {rd }}$ and $4^{\text {th }}$ weeks after surgery.

\section{Method of scarification:}

The animals were sacrificed by excess sulphuric ether inhalation. The right mandible was separated from the left by a median sagittal incision.

\section{Methods of measuring the healing extraction socket:}

A bone caliper (40mm Weiss Modified Curved Bone Caliper, Germany) was used to measure the buccolingual ridge width, which is the distance between the mid-buccal point and mid- lingual point around the tooth that is exactly under the extraction socket site, shortly after scarification. Mid-buccal height was also measured from a mid-point on the coronal surface of the extraction socket to an opposing point at the base of the mandible (17).

\section{STATISTICAL ANALYSIS}

The collected data were statistically analyzed, for the length and width of the mandible at extraction socket site of both control and experimental groups. All data were represented as mean and standard deviation (mean - S.D.). To investigate the morphological differences between the four experimental and four control groups, analysis of variance (ANOVA) statistical procedures were performed. All statistical analyses were performed using the SPSS 
(Statistical Package for the Social Sciences, SPSS 13; SPSS, Chicago, IL, USA). A result was considered statistically significant at $\mathrm{p}<0.05$.

\section{RESULTS}

Knowing that the average height of the socket at time of extraction, measured in all the samples, was an average of 6 $\mathrm{mm}$ and the width was an average of $5 \mathrm{~mm}$ as well. The relative height of the mandible at the extraction socket site of the experimental and control groups were compared (Table 1\& Figure 1). There was no significant difference between the two groups at $1^{\text {st }}, 2^{\text {nd }}$ and $3^{\text {rd }}$ weeks. The relative height of the mandible at the extraction socket site in the control group was significantly smaller compared to the height of the mandible in the experimental group at $4^{\text {th }}$ week.

Socket height in the experimental group at the 1st week was significantly than the height at the $4^{\text {th }}$ week of the same group, while there was no significant difference between the mandible heights in the control group throughout the 4 weeks.

Table 1: Comparison between the experimental and control groups according to height of the mandible at the extraction socket site

\begin{tabular}{|c|c|c|c|c|c|c|}
\hline Height & $1^{\text {st }}$ Week & $2^{n^{\mathrm{n}<1}}$ Week & $3^{r<1}$ Week & $4^{\text {th }}$ Week & $\mathbf{F}$ & $\mathbf{P}$ \\
\hline $\begin{array}{c}\text { Control }(n= \\
5) \\
\text { Min. - Max. } \\
\text { Mean } \pm \text { SD. } \\
\text { Median }\end{array}$ & $\begin{array}{c}3.50-4.50 \\
4.0 \pm 0.50 \\
4.0\end{array}$ & $\begin{array}{c}3.0-4.503 .90 \\
\pm 0.654 .0\end{array}$ & \begin{tabular}{|c}
$4.0-4.754 .40 \pm$ \\
0.384 .50
\end{tabular} & $\begin{array}{c}3.75-4.754 .20 \\
\pm 0.514 .0\end{array}$ & 0.771 & 0.532 \\
\hline $\mathbf{P}$ & & 0.815 & 0.282 & 0.477 & & \\
\hline \begin{tabular}{|c} 
Experimental \\
$(\mathrm{n}=5)$ \\
Min. - Max. \\
Mean \pm SD. \\
Median
\end{tabular} & $\begin{array}{c}3.0-5.0 \\
4.20 \pm 0.91 \\
4.50\end{array}$ & $\begin{array}{c}4.0-5.04 .45 \\
\pm 0.454 .50\end{array}$ & $\begin{array}{c}4.0-5.04 .70 \pm \\
0.455 .0\end{array}$ & $\mid \begin{array}{c}5.0-6.05 .70 \pm \\
0.456 .0\end{array}$ & $10.921 *$ & $0.001 *$ \\
\hline $\mathbf{P}$ & & 0.569 & 0.089 & $0.013^{*}$ & & \\
\hline 'R. & 0.678 & 0.158 & 0.286 & $0.001 *$ & & \\
\hline
\end{tabular}

F: $F$ test (ANOVA) with repeated measures

$\mathrm{p}$ : $\mathrm{p}$ value for $\mathrm{F}$ test (ANOVA) with repeated measures (LSD) for comparing between $1^{\text {st }}$ Week and each other period in each group 'pi: $p$ value for Student $t$-test for comparing between the two studied groups *: Statistically significant at $\mathrm{p}<0.05$

The buccolingual width of the mandible at the extraction socket site of the experimental and control groups were also compared (Table $2 \&$ Figure 2). There was significance difference between mandible width of both groups at the $1^{\text {st }}$, $3^{\text {rd }} \& 4^{\text {th }}$ weeks, whereas the control group showed greater bone resorption.

Socket width in the experimental group at the $4^{\text {th }}$ week was significantly larger than the width at the $1^{\text {st }}$ week of the same group. Also the socket width in the control group at the $4^{\text {th }}$ week showed significant greater thickness than the socket width at the $1^{\text {st }}$ week of the same group, indicating higher rates of resorption in the $1^{\text {st }}$ week than the $4^{\text {th }}$ week of both groups.

The obtained values of the height and width at the fourth week in the experimental groups, in relation to the normal height and width of the rat jaw, indicate restoring of the normal architecture of the tissue.

\section{DISCUSSION}

Simvastatin is a common cholesterol-lowering drug used for prevention and treatment of cardiovascular diseases.
Recent studies have shown that it is also capable of promoting bone formation in vitro and in vivo. Since simvastatin undergoes extensive first-pass extraction in the liver after oral administration, the availability of the drug to the general circulation is low $(<5 \%)$. This pharmacokinetic characteristic leads to a lower concentration of the drug in other tissues. Since the successful use of simvastatin to promote bone formation in vivo depends on a high local concentration, there have been continuous efforts to find an appropriate delivery system. The results of the present study suggest that simvastatin stimulates bone regeneration when it is locally administered into extraction socket of mandibular alyeolar bone (1).

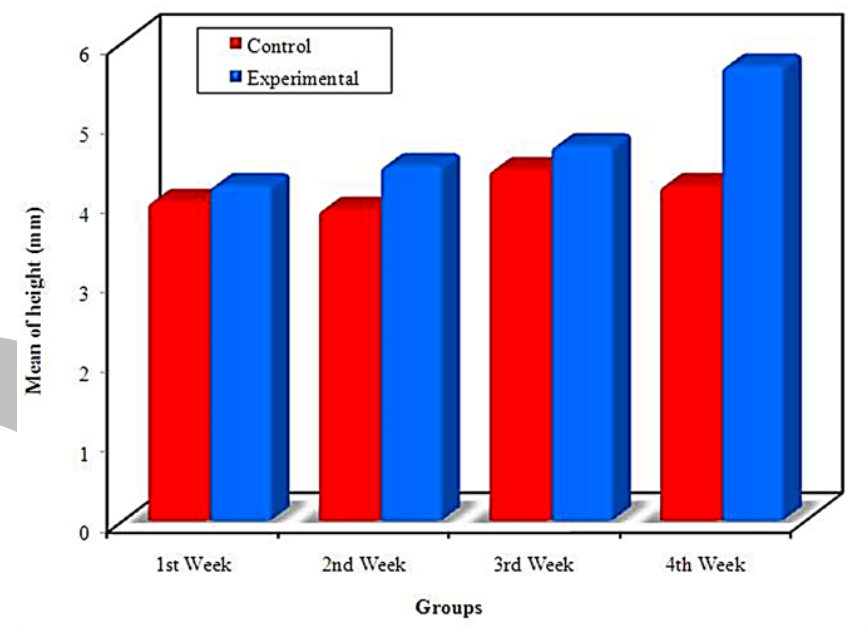

Figure 1: Comparison between the experimental and control groups according to height of the mandible at the extraction socket site.

Table 2: Comparison between the experimental and control groups according to width of the mandible at the extraction socket site.

\begin{tabular}{|c|c|c|c|c|c|c|}
\hline Width & $1^{\text {st }}$ Week & $2^{\text {nd }}$ Week & $3^{\text {rd }}$ Week & $4^{\text {th }}$ Week & $\mathbf{F}$ & $\mathbf{P}$ \\
\hline $\begin{array}{l}\text { Control }(n=5) \\
\text { Min. - Max. } \\
\text { Mean = SD. } \\
\text { Median }\end{array}$ & $\begin{array}{c}1.50-2.50 \\
2.0=0.35 \\
2.0\end{array}$ & $\begin{array}{c}1.75-2.75 \\
2.20=0.41 \\
2.0\end{array}$ & $\begin{array}{c}1.75-2.50 \\
2.0=0.31 \\
2.0\end{array}$ & $\mid \begin{array}{c}2.75-3.75 \\
3.25=0.47 \\
3.0\end{array}$ & $16.332 “$ & $<0.001$ “ \\
\hline $\mathbf{P}$ & & 0.405 & 1.000 & 0.002 “ & & \\
\hline $\begin{array}{c}\text { Experimental } \\
(\mathbf{n}=\mathbf{5}) \\
\text { Min. - Max. } \\
\text { Mean = SD. } \\
\text { Median }\end{array}$ & $\begin{aligned} & 2.0-3.0 \\
& 2.55=0.37 \\
& 2.50\end{aligned}$ & $\begin{array}{c}2.0-2.75 \\
2.55=0.33 \\
2.75\end{array}$ & $\begin{array}{c}2.75-4.0 \\
3.50=0.59 \\
3.75\end{array}$ & 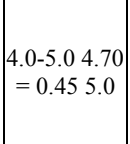 & 20.948 “ & $<0.001$ “ \\
\hline $\mathbf{P}$ & & 1.000 & $0.06 \mathrm{~S}$ & $0.002^{\prime \prime}$ & & \\
\hline 'Pi & 0.043” & 0.174 & $0.002 “$ & $0.001 “$ & & \\
\hline
\end{tabular}

F: F test (ANOVA) with repeatedmeasures

$p$ : $p$ value for $F$ test (ANOVA) with repeatedmeasures (LSD) for comparing between $1^{3:}$ Week and each otherperiod in each group: $\mathrm{p} ; \mathrm{p}$ value for Student $\mathrm{t}$-test for comparing bet ween the two studied groups *: Statistically significant at p i 005

It was found that orally administered simvastatin was processed in the liver, yielding low amounts of the drug available for bone. Thus, a gel (chitosan) was chosen as a carrier to topically deliver simvastatin into the bone extraction sockets created. Chitosan is an excellent natural polymer to consider as a material for the construction of 
$3 \mathrm{D}$ scaffolds for bone tissue engineering. It is biodegradable, biocompatible, has antibacterial, wound healing, and bioadhesive properties (12).

As the statistical analysis revealed that bone formation started earlier in the simvastatin-treated rats than in the controls, since bone width in the experimental group was significantly greater than that of the control group at the $1^{\text {st }}$ week.

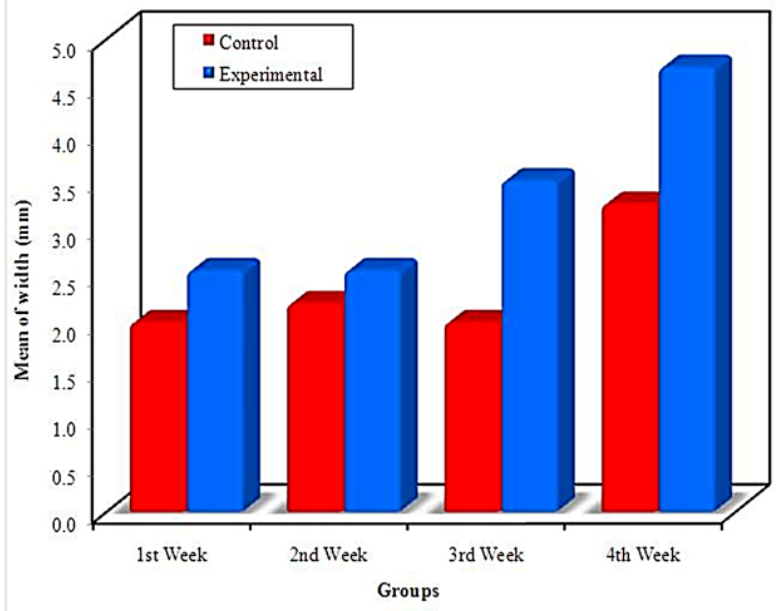

Figure 2: Comparison between the experimental and control groups according to width of the mandible at the extraction socket site.

Additionally, the rate of both height and width resorption was higher in the control group than in the experimental group at the $4^{\text {th }}$ week.

In this study, bone resorption was only observed in the control specimens, especially at the last week. The absence of resorptive activity in the simvastatin-treated mandibles was due to the inhibition of the fusion of osteoclastic cell precursors or disruption of the actin ring of active osteoclasts (18).

\section{CONCLUSIONS}

Local simvastatin administration increased alveolar crest height and prevented local alveolar bone loss. Thus, providing additional improvement of bone quantity.

Moreover, topical application is a convenient procedure in oral surgery. However, further studies regarding the optimal dose of the drug, different vehicles, or in association with scaffolds for bone growth are still necessary.

\section{CONFLICT OF INTEREST}

The authors declare that they have no conflicts of interest.

\section{REFERENCES}

1. Drake MT, Clarke BL, Khosla S. Bisphosphonates: mechanism of action and role in clinical practice. Mayo Clin Proc 2008; 83: 1032-45.

2. Endo A. A historical perspective on the discovery of statins. Proc Jpn Acad Ser B 2010; 86: 484-93.

3. Mundy G, Garrett R, Harris S, Chan J, Chen D, Rossini G, et al. Stimulation of bone formation in vitro and in rodents by statins. Science 1999; 286: 1946-9.

4. Marie PJ, Debiais F, Hay E. Regulation of human cranial osteoblast phenotype by FGF-2, FGFR-2 and BMP-2 signaling. Histol Histopathol 2002; 17: 877-85.
5. Zhang Y, Bradley AD, Wang D, Reinhardt RA. Statins, bone metabolism and treatment of bone catabolic diseases. Pharmacol Res 2014; 88: 53-61.

6. Marks SC, Hermey DC. The structure and development of bone. In: Bilezekian JP, Raisz LG, Rodan GA, editors. Principles of bone biology. San Diego: Academic Press; 1996: 3-24

7. Huebsch RF, Hansen LS. A histopathologic study of extraction wounds in dogs. Oral Surg Oral Med Oral Pathol 1969; 28:187-96

8. Guglielmotti MB, Cabrini RL. Alveolar wound healing and ridge remodeling after tooth extraction in the rat. a histologic, radiographic and histometric study. J Oral Maxillofac Surg 1985; 43: 359-64.

9. Smith N. A comparative histological and radiographic study of extraction socket healing in rat. Australian Dental J 1974; 250-4.

10. Woo JT, Kasai S, Stern PH, Nagai K. Compaction suppresses bone resorption by inhibiting the fusion of perfusion osteoclasts and disrupting the actin ring in osteoclasts. J Bone Miner Res 2000; 15: 650-62.

11. Fiedler J, Leucht F, Waltenberger J, Dehio C, Brenner RE. et al. VEGF-A and PlGF-1 stimulate chemotactic migration of human mesenchymal progenitor cells. Biochem Biophys Res Commun 2005; 334: 561-8.

12. Costa-Pinto AR, Reis RL, Neves NM. Scaffolds based bone tissue engineering: the role of chitosan. Tissue Eng Part B Rev. 2011; 17:331-347.

13. Parfitt AM. The cellular basis of bone remodeling: the quantum concept reexamined in light of recent advances in the cell biology of bone. Calcif Tissue Int 1984; 36: S37-45.

14. Grasser WA, Baumann AP, Petras SF, Harwood HJ, Devalajara R, Renkiewicz R, et al. Regulation of osteoclast differentiation by statins. J Musculoskelet Neuronal Interact 2003; 3: 53-62.

15. Perchyonok VT, Reher V, Zhang S, Basson N, Grobler S. Evaluation of Nystatin Containing Chitosan Hydrogels as Potential Dual Action Bio-Active Restorative Materials: in Vitro Approach. J Funct Biomater 2014; 5: 259-72.

16. Ismail FA. Design and in vitro evaluation of polymeric formulae of simvastatin for local bone induction. Drug Dev Ind Pharm 2006; 32: 1199-206.

17. Kiliaridis, S.; Thilander, B.; Kjellberg, H.; Topouzelis, N. $\&$ Zafiriadis. Effect of low masticatory function on condylar growth: a morphometric study in the rat. Am. J. Orthod. Dentofacial Orthop., 1999: 116:121-5.

18. Yazawa AH, Zimmermann B, Asami Y, Bernimoulin JP. Simvastatin promotes cell metabolism, proliferation, and osteoblastic differentiation in human periodontal ligament cells. J Periodontol 2005; 76: 295-302. 